\title{
Development of Neuromuscular Specificity in the Grasshopper Embryo: Guidance of Motoneuron Growth Cones by Muscle Pioneers ${ }^{1}$
}

\author{
ELDON E. BALL, ${ }^{\star} \ddagger$ ROBERT K. HO, ${ }^{\star, 2}$ AND COREY S. GOODMAN ${ }^{*, 3}$ \\ * Department of Biological Sciences, Stanford University, Stanford, California, 94305 and $\ddagger$ Department of Neurobiology, Research \\ School of Biological Sciences, Australian National University, P. O. Box 475, Canberra City, A. C. T. 2601, Australia
}

\begin{abstract}
In the grasshopper embryo, neuromuscular specificity develops between individual identified motoneurons whose cell bodies are located in the central nervous system, and specific skeletal muscles in the periphery. We previously reported on a class of large mesodermal cells, called muscle pioneers (MPs), that arise early in development (Ho, R. K., E. E. Ball, and C. S. Goodman (1983) Nature 301: 66-69). We suggested that the MPs might be involved in orchestrating the coordinated development of nerve and muscle. In this paper, we describe the development of the MP for coxal muscle 133a in the metathoracic limb bud, and its innervation by two excitatory motoneurons (fast, $D_{f}$, and slow, $D_{s}$ ). Although many motoneuron growth cones extend out of nerve 5 and quite likely come in contact with the $133 \mathrm{a}$ MP between $35 \%$ and $45 \%$ of development, only $D_{f}$ and $D_{s}$ display a high affinity for its surface; the other motoneurons innervate more distal leg muscles. When the 133a MP is ablated before arrival of motoneurons in the limb bud, the $D_{\text {f }}$ growth cone extends past the location where it normally gets off nerve 5 and continues to extend distally along the same pathway taken by its sibling motoneuron. Although there is a mass of small mesodermal cells in the area where the differentiated coxal muscle 133a normally forms, evidently it does not provide the necessary guidance cue for the $D_{1}$ growth cone. These results indicate the important role played by MPs in the specific guidance of motoneuron growth cones in the grasshopper embryo.
\end{abstract}

in vertebrate embryos, a precise pattern of connectivity develops between pools of motoneurons in the spinal cord and specific skeletal muscles. For example, in the chick hindlimb, motoneuron

Received August 20, 1984; Revised December 3, 1984;

Accepted December 4, 1984

${ }^{1}$ We thank Peter Bräunig, Reinhold Hustert, and Paul Whitington for help in identifying muscle $133 \mathrm{a}$, Kerrie Ruth for help with the color figure, and Paul Whitington for comments on our manuscript. This work was supported by Australian National University (E. E. B.), a Department of Child Health and Hurrlan Development, Developmental Biology predoctoral traineeship (R. K. $H$.), and grants from the National Institutes of Health and the National Science Foundation (C. S. G.).

${ }^{2}$ Present address: Department of Zoology, University of California, Berkeley, CA 94720

${ }^{3}$ To whom correspondence should be addressed, at Department of Biological Sciences, Stanford University, Stanford, CA 94305. growth cones extend into the periphery along stereotyped pathways and enter the appropriately located masses of mesodermal cells early in development before myotube formation and the differentiation of mature muscles (Lance-Jones and Landmesser, 1981a). The results of experimental manipulations have suggested that motoneuron growth cones are guided by a series of local cues both at the base of the limb bud and within the limb bud itself (Lance-Jones and Landmesscr, 1980a, b, 1981 b; Fcrguson, 1983; Whitclaw and Hollyday, 1983a, b, c).

In the grasshopper embryo, a precise pattern of connectivity develops between individual identified motoneurons in the segmental ganglia and specific skeletal muscles. With only a few rather than thousands of motoncurons innervating a particular muscle, this simple system offers the opportunity for a detailed analysis of the mechanisms underlying neuromuscular specificity. Our goal in these studies is to understand how muscles develop in the proper places, and how motoneuron growth cones find their correct muscles.

On their way out of the CNS and into the periphery toward their appropriate muscles, the growth cones of most motoneurons in the grasshopper embryo make a series of cell-specific choices which include repeated choices of which axon fascicle to follow. These observations are similar to the well studied examples in the grasshopper CNS of growth cone guidance by selective fasciculation (e.g., Raper et al., 1983c, 1984; Bastiani et al., 1984, 1985; Goodman et al., 1984). However, the major difference between motoneurons navigating in the periphery and interneurons navigating in the CNS is that, at some point, the growth cones of motoneurons are obliged to leave the surfaces of other neurons (the axon fascicles) and enter the appropriate mass of mesodermal cells. It is thus reasonable to speculate that motoneurons are guided by a hierarchy of cellular cues, including specific guidance cues in the pre-muscle mesoderm that identify the future location of particular muscies.

We previously described a class of large mesodermal cells, called muscle pioneers (MPs), that arise early in development when the embryonic environment is relatively simple and distances are short (Ho et al., 1983). The MPs at this stage do not display differentiated muscle properties. Rather, the growth and association of particular MPs with specific sites along the ectoderm suggested that the MPs erect a scaffold used by the mass of mesodermal cells for their later development into differentiated muscles. Furthermore, the specific association between identified motoneuron growth cones and particular MPs suggested the hypothesis that the MPs are differentially labeled and provide specific guidance cues for motoneuron growth cones.

MPs in general share the following characteristics (Ho et al., 1983). First, they appear in the mesoderm early in development when the terrain is relatively simple and distances are short, and long before the appcarance of differentiated muscle fibers. Second, their adhe sive properties differ from those of other mesodermal cells in that 
they often flatten and adhere to the ectodermal epithelium (or its overlying basement membrane), whereas other mesodermal cells do not. Third, they extend large growth cone-like processes across the inner surface of the ectoderm or its basement membrane. These processes stop and insert into the ectoderm at locations which seem to delineate the future muscle insertion sites. Fourth, by their inscrtion at the futurc sitc of ectodermal invagination, they appcar to be intimately involved in the morphogenesis of tendons (called apodemes in insects). Fifth, other smaller mesodermal cells cluster around each MP and, later in development (when the terrain is more complex), fuse together (and with the MP) and form differentiated muscle fibers (Ball and Goodman, 1985a, b), using the long processes and ectodermal insertions of the MPs as a scaffold. Sixth, motoneuron growth cones seem to use the muscle pioneers as one of their guidance cues, as investigated in more detail in this paper It appears that every muscle in the grasshopper embryo is preceded by the earlier appearance of an MP; this is certainly the case in the metathoracic leg where every muscle in the adult is preceded by an MP in the embryo (Ball et al., 1985).

In this paper, we describe the development of the MP for coxal muscle 133a in the metathoracic limb bud and its innervation by two excitatory motoneurons (fast, $D_{f}$ and slow, $D_{s}$ ). We then report on ablation experiments which confirm the important role played by the 133a MP in the specific gutidance of the $D_{f}$ growth cone

\section{Materials and Methods}

Identification of coxal muscle 133a and innervating motoneurons in the adult. Our study was initiated by the observation that, in preparations stained with the 1-5 monoclonal antibody (MAb), a single motoneuron growth cone could predictably be seen leaving nerve 5 (N5) and approaching an MP in the coxa at 40 to $41 \%$ of embryonic development. We thought this would be a good system in which to describe and manipulate the development of neuromuscular specificity. However, we were initially unable to identify either the motoneuron or the muscle at this stage of development.

Fortunately, we were able to identify the muscle from the literature because it is known that only one muscle in the coxa-trochanter of the grasshopper is innervated from N5 (Campbell, 1961; Bräunig et al., 1981; Bräunig, 1982) the rest are innervated from N3 and N4. The muscle of interest, as described under "Results," is clearly innervated from N5. This muscle, the trochanteral depressor 133a (Snodgrass, 1929), is innervated by branch NbA and is the only muscle so innervated.

In order to identify the motoneurons innervating coxal muscle $133 \mathrm{a}$, the branch N5A was cut in the periphery and backfilled with $5 \% \mathrm{CoCl}_{2}$. Following development in ammonium sulfide the ganglion was intensified using the technique of Bacon and Altman (1977).

Embryos. Embryonic development of the grasshopper Schistocerca americana takes 20 days from fertilization to hatching at $33^{\circ} \mathrm{C}$; thus, $5 \%$ of development equals $24 \mathrm{hr}$ and $1 \%$ equals $4.8 \mathrm{hr}$. Embryos were staged to the nearest $5 \%$ according to the system of Bentley et al. (1979) and to the nearest $1 \%$ between $35 \%$ and $45 \%$ by the precise morphology of the motathoracic limb bud. Only large, healthy, synchronized clutches of eggs were used for these studies. Within a clutch there is some variability in the timing of events described here, and even more between clutches. We are not able to say what portion of this variability is due to inaccuracies in staging, slight differences in environmental conditions experienced by the embryos, or actual temporal variability in the relationship of internal developmental events versus the external morphological features used for staging. Most of the events described here have a variability of about $\pm 1 \%$.

Dissection and Nomarski observations. Embryos were dissected out of the egg case in isotonic saline (grams per liter: $\mathrm{NaCl}, 8.76 ; \mathrm{KCl}, 0.22 ; \mathrm{CaCl}_{2}$. $2 \mathrm{H}_{2} \mathrm{O}, 0.29 ; \mathrm{MgSO}_{4} \cdot 7 \mathrm{H}_{2} \mathrm{O}, 0.25$; TES, $1.15 ; \mathrm{pH} 7.0$ ), pinned out in coffins cut in Sylgard-covered slides, and viewed with a Leitz $\times 50$ water immersion lens and Zeiss Nomarski optics (Raper et al., 1983a). Many of the cells and developmental events described in this paper can be directly observed by viewing the metathoracic limb bud in the living cmbryo with Nomarski optics.

Antibody treatment. For staining with the 1.5 monoclonal antibody (Chang et al., 1983), the embryos were transferred to $2 \%$ paraformaldehyde in Millonig's buffer, where the legs were unfolded and held with the fernur extended from the body until initial fixation had occurred. Following 30 to 60 min of fixation embryos were rinsed in Millonig's buffer (Bate, 1976). Embryos younger than $40 \%$ were then placed in a $0.1 \mathrm{~m}$ glycine solution in Millonig's buffer to take up any aldehyde remaining from fixation. During the period of development considered here, the chitinous embryonic cuticle is appearing and becoming progressively thicker. This cuticle must be made permeable in order to get antibodies into the leg. For a $40 \%$ embryo, treatment with 0.1 $\mathrm{mg} / \mathrm{ml}$ of chitinase (Sigma Chemical $\mathrm{Co}$.) in Millonig's buffer ( $\mathrm{pH} 7.3$ to 7.5 ) for $12 \mathrm{hr}$ at $33^{\circ} \mathrm{C}$ was sufficient; chitinase concentration and incubation time were progressively increased for older animals. After glycine or chitinase treatments, the tissue was rinsed thoroughly in phosphate-buffered saline (PBS). I The embryos were then placed in a PBS solution containing the $1-5$ monoclonal antibody (derived from tissue culture supernatant), $2 \%$ bovine serum albumin, and $0.25 \%$ Triton X-100 at $5^{\circ} \mathrm{C}$ for $24 \mathrm{hr}$. Following a PBS rinse, the tissue was placed in a PBS solution containing horseradish peroxidase (HRP)-conjugated rabbit anti-mouse lgG (Miles Laboratories), 2\% hovine serum albumin, and $0.25 \%$ Triton $\mathrm{X}-100$ at $5^{\circ} \mathrm{C}$ for $24 \mathrm{hr}$. The embryos were then rinsed in PBS, treated with the substrate 3,3-diaminobenzidine $(0.5 \mathrm{mg} / \mathrm{ml})$ and hydrogen peroxide $(0.003 \%)$ in PBS, dehydrated and cleared through a glycerol series, and drawn and photographed in whole mount.

The 1-5 MAb has been described in detail by Chang et al. (1983); it recognizes a cytoplasmic antigen expressed in a subset of neurons and mesodermal cells in the grasshopper embryo. Within the limb bud, it selectively stains the mesodermally derived MPs at early stages of development (Ho et al., 1983) in addition to the ectodermally derived peripheral neurons and the axons of central motoneurons as they grow out into the periphery (Ho and Goodman, 1982)

Intracellular dye injections. Cells were visualized with Nomarski optics and penetrated with intracellular microelectrodes for dye injections. For Lucifer Yellow (LY) fills, electrodes contained 10\% LY (Aldrich) in $0.2 \mathrm{M}$ sodium acetate, and hyperpolarizing current was used for iontophoresis of LY into the cell. Embryos containing LY-filled cells were processed after fixation using a serum antibody against LY (anti-LY), a secondary goat antirabbit antibody coupled to HRP (Miles), and HRP histochemistry as described above (Taghert et al., 1982). Other cells were filled with a mixture of $4 \%$ HRP (Boehringer Mannheim, grade $\mathrm{I}$ ) and $1 \%$ LY made up in $0.15 \mathrm{M}$ sodium acetate. This mixture was centrifuged at 20,000 rpm for 5 min (Beckman Microfuge) and the supernatant was used for injection. The LY added to the HRP was advantageous for providing a rapid check that the pressure injection system was working and for revealing those cells which were dye coupled to the 133a MP. The HRP stays within the 133a MP itself, not crossing gap junctions which are crossed by $L Y$. The dye mixture was pressure injected using a Picospritzer (General Valve Corp.) at 420 to $560 \mathrm{gm} / \mathrm{cm}^{2}$. Injected embryos were fixed immediately in $2 \%$ paraformaldehyde in Millonig's buffer. They were then washed, treated with chitinase for a variable time depending upon age, and washed again; the HRP was then visualized using diaminobenzidine and either $\mathrm{H}_{2} \mathrm{O}_{2}$ or a glucose oxidase reaction mixture (Raper et al., 1983b). This was followed by clearing through a glycerol series and viewing and photography in whole mount.

Cell ablations. Cell ablations were accomplished by using a microelectrode to impale the cell. A large depolarizing current $(\sim 10 \mathrm{nA})$ was briefly passed into the cell, and the nucleus of the cell was disrupted by moving the microelectrode under visual control. The 133a MP could be visualized with Nomarski optics and easily impaled. As described under "Results," the 133a MP was killed before it finished migrating to its final position, thus avoiding any damage to other mesodermal cells in the vicinity where the 133a MP normally becomes innervated. These manipulations were done under sterile conditions, and the embryos were then placed into tissue culture for $48 \mathrm{hr}$ (Raper et al., 1984; Taghert et al., 1984). Tissue culture medium consisted of Roswell Park Memorial Institute Medium 1640 (GlBCO) supplemented with $2 \mathrm{gm} /$ liter of sodium bicarbonate, $0.29 \mathrm{gm} /$ liter of glutamine, $0.11 \mathrm{gm} /$ liter of sodium pyruvate, $2.0 \mathrm{gm} /$ liter of glucose, 50,000 units of penicillin, and $50,000 \mu \mathrm{g}$ of streptomycin. Fetal calf serum was added to a concentration of $10 \%$ and was further supplemented with $3.0 \mathrm{gm} /$ liter of glycine, $7.8 \mathrm{mg} /$ liter of bovine insulin (Sigma), $150 \mu \mathrm{g} /$ liter of $\beta$-ecdysterone (Sigma), and 0.5 $\mu \mathrm{g} / \mathrm{ml}$ of juvenile hormone I (Sigma). Cultures were maintained in a moist incubator in a $5 \% \mathrm{CO}_{2}$ atmosphere at $30^{\circ} \mathrm{C}$.

\section{Results}

This paper describes the development of coxal muscle 133a and its innervation in the grasshopper embryo. However, before describing the development of this simple neuromuscular system, we first describe the location of this muscle and establish that it is innervated by three identified motoneurons in the adult. Although we have studied the development of the extensor tibiae and flexor tibiae muscles in the metathoracic limb bud (Ball and Goodman, 1985a, b) we focus here on coxal muscle 133a because, in the embryo, it 
proximal $\longrightarrow$ distal

Figure 1. Schematic drawing of the metathoracic leg of the adult grasshopper showing the parts of the leg and the locations of the major muscles and tendons (apodemes; in black). In the coxa, only muscle $133 \mathrm{a}$, a trochanteral depressor muscle, is labeled (stippled region). This muscle is the topic of this paper. The extent of the extensor tendon is also drawn greatly reduced in the dorsoventral plane in order to show the arrangement of the ETi muscle bundles. AETi, accessory extensor tibiae muscle; AFITi, accessory flexor tibiae muscle; DTa, depressor tarsus muscle; DTr, trochanteral depressor muscle (133a); LeTa, levator tarsus muscle; $R U 1$, retractor unguis muscle $1 ; R U 2$, claw retractor muscle $2 ; R U 3$, claw retractor muscle 3.

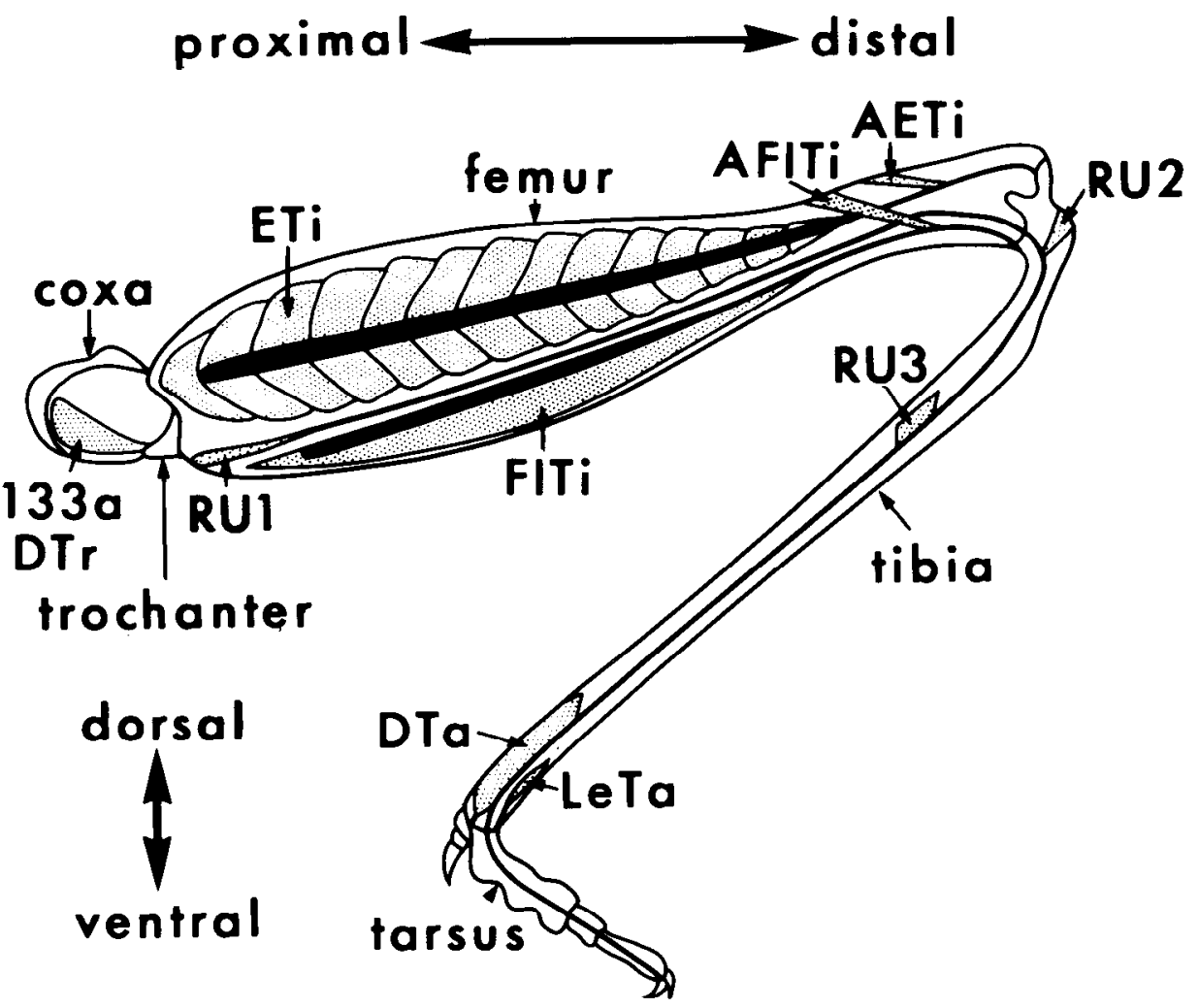

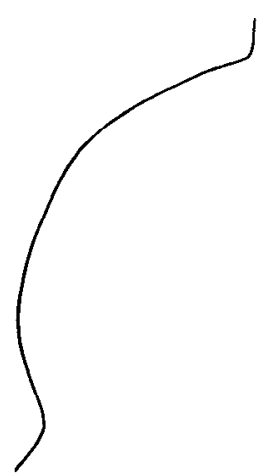
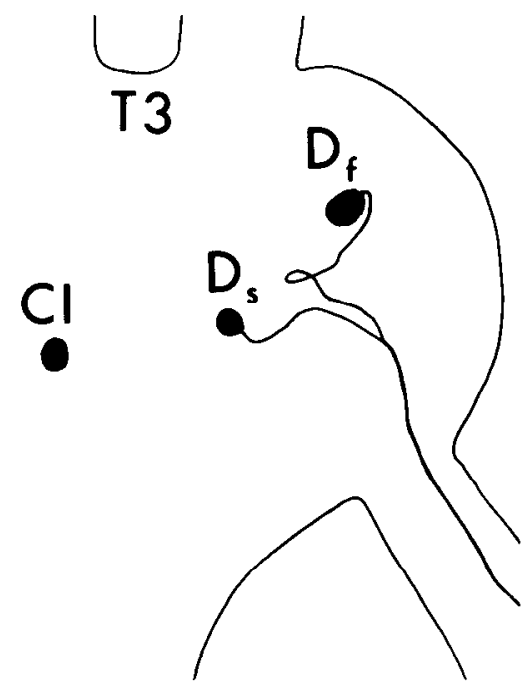

Figure 2. The three identified motoneurons which innervate the $133 \mathrm{a}$ muscle in the adult grasshopper. This drawing shows the pattern of motoneuron cell bodies as revealed by cobalt backfills of the nerve branch innervating the 133a muscle. Cells are named on the basis of their homology to the comparable cockroach motoneurons (see the text). The two excitatory motoneurons, $D_{t}$ and $D_{s}$, have ipsilateral cell bodies. The cell body of the inhibitory motoneuron, $\mathrm{Cl}$, is located contralateral near the midline; its axon was not visible in unintensified preparations.

is especially favorable for studying neuromuscular development due to its accessible location and simple innervation pattern.

Innervation of coxal muscle $133 a$ in the adult. The overall organization of the muscles and tendons of the adult metathoracic leg is shown schematically in Figure 1. The coxa contains many muscles, but for simplicity, the only coxal muscle shown in Figure 1 is muscle 133a, a trochanteral depressor muscle, which is the topic of this paper. Three major nerves exit the metathoracic ganglion and enter the metathoracic leg: nerves 3,4 , and 5 . Muscle $133 a$ is the only coxal muscle which receives its innervation from N5. With the exception of one motoneuron (superior extensor tibiae, SETi), all of the muscles in the more distal leg segments (the femur and tibia) are innervated from N5. However, with the exception of muscle $133 \mathrm{a}$, all of the muscles in the coxa are innervated from N3 and N4 (Bräunig, 1982).

Muscle 133a appears to be homologous to one of the well studied cockroach trochanteral depressor muscles which is innervated by five identified motoneurons. These are two excitatory motoneurons $\left(D_{f}\right.$, the fast depressor, and $D_{s,}$ the slow depressor) and three inhibitory motoneurons $(\mathrm{Cl}$, the common inhibitor, and two other inhibitors with branches restricted to N5) (Pearson and lles, 1971; lles, 1972; Pitman et al., 1972, 1973; Pearson and Fourtner, 1973). In the cockroach, as in all orthopteran insects, the cell bodics of the inhibitory motoneurons cluster near the ventral midline, whereas the cell bodies of the excitatory motoneurons are scattered more laterally.

When we backfilled the branch of N5 innervating muscle 133a of the grasshopper with cobalt dye (Fig. 2), we consistently filled neurons corresponding in position and morphology to $D_{f}$ and $D_{s}$ of the cockroach. Less consistently, we filled a single cell near the ventral midline corresponding in position to $\mathrm{Cl}$, the common inhibitor neuron. Burrows (1975) has reported the neurons we have designated $D_{1}$ and $D_{s}$ in backfills of N5A in the grasshopper Schistocerca, and Bräunig (1982) reported the same three neurons described here as innervating muscle 133a in two species of grasshopper, Schistocerca and Locusta. It is therefore likely that the two additional inhibitors found in the cockroach Periplaneta do not innervate muscle $133 \mathrm{a}$ in the grasshopper Schistocerca that we have studied.

The cells which we have called $D_{f}$ (ventral cell body) and $D_{s}$ (dorsal cell body) have ipsilateral cell bodies, $D_{f}$ being the more anterior of the two. We assume that these two cells are excitatory motoneurons because of their lateral cell body location and apparent homology to morphologically similar cells in the cockroach. The ventral midline cell is clearly the identified inhibitory neuron $\mathrm{Cl}$ (Burrows, 1973). This identification is unequivocal because $\mathrm{Cl}$ is the only leg motoneuron with a contralateral cell body (Whitington and 

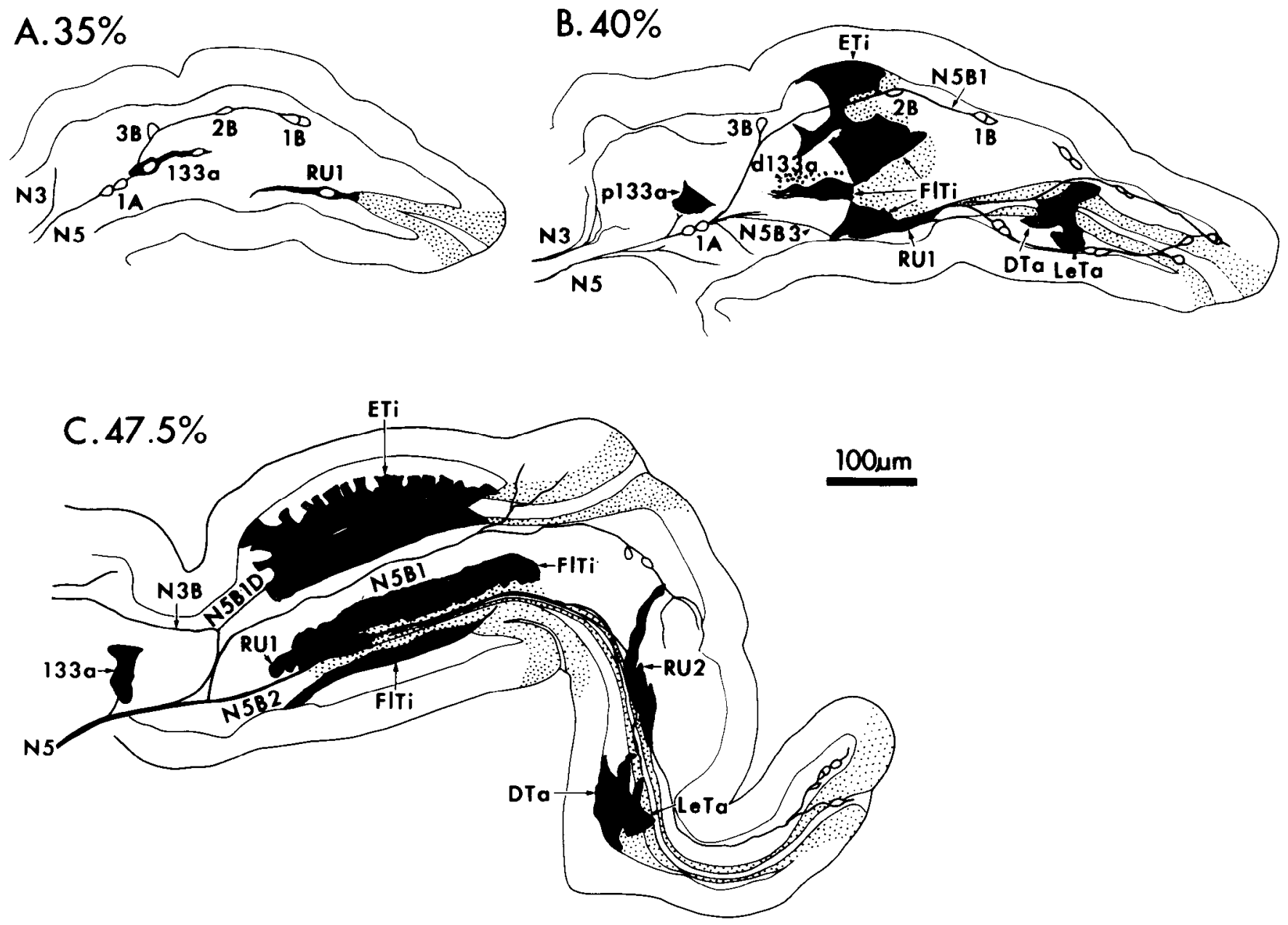

Figure 3. Embryonic development of the metathoracic limb bud at $35 \%(A), 40 \%(B)$, and $47.5 \%(C)$ of development. Ihe drawings show the major features in the development of nerves and muscles in the limb bud, in particular showing the location and context of the MP for the trochanteral depressor muscle 133a, the topic of this paper. MPs are shown in black and the ectoderm of the tendon invaginations is stippled. Note that, even though they are drawn as single large black masses, the MPs for many of the muscles are either multicellular (e.g., FITi) or large multinucleate cells (e.g., ETi) (Ball and Goodman, 1985a, b). Abbreviations: 1A, 1B, 2B, 3B, pioneer neurons (Bentley and Keshishian, 1982; Ho and Goodman, 1982); 133a, the trochanteral depressor muscle pioneer (at 40\%, this MP divides into two cells, one proximal ( $p 133 a$ ) and the other distal (d133a); the d133a MP then degenerates and is seen as debris); DTa, tarsal depressor MP; LeTa, levator tarsus MP; N3, N3B, nerve 3 and branches; N5, N5B1,N5B2, N5B3, N5B1D, nerve 5 and branches; $R U 1$, retractor unguis MP; $R U 2$, retractor of the claws MP.

Seifert, 1981). Furthermore, our intensified cobalt backfills reveal that the neuron in question has axons exiting the ganglion via contralateral N3, N4, and N5, another unique characteristic of $\mathrm{Cl}$ (Burrows, 1973). For these reasons we have called the cells by the same names used in the cockroach, $D_{\mathrm{f}}, \mathrm{D}_{3}$, and $\mathrm{Cl}$, and assume that they are, respectively, two excitors and one inhibitor. It should also be pointed out that most of the motoneurons innervating more distal muscles extend out of the same nerve as do the three motoneurons innervating 133a.

Overall development of the metathoracic limb bud. Gastrulation in insects (summarized in Anderson, 1972) transforms the single layer of the blastoderm into two germ layers, the presumptive mesodermal cells migrating through the gastral groove to become the inner or dorsal layer. The outer (ventral) layer of ectoderm gives rise to epidermis and nervous system; the inner (dorsal) layer of mesoderm gives rise to muscle and some other body parts. The inner layer spreads laterally and, as segmentation proceeds in the ectoderm, cleaves into segmental groups of mesodermal cells. The thick lateral segmental masses of mesodermal cells develop into paired, hollow somites surrounding a coelomic cavity. Each somitic mass spreads dorsolaterally to form dorsal body muscles; ventromedially to form extrinsic limb muscles, ventral longitudinal muscles, and ventral transverse muscles; and ventrolaterally to form the intrinsic muscles of the limb bud, including coxal muscle 133a described here.

At $25 \%$ of development, the ventrolateral mesoderm is within the lumen of the limb bud and appears as a homogeneous mass of small undifferentiated cells. By $30 \%$, the first MPs are already recognizable within the mesoderm in the limb bud by 1-5 MAb staining and by their tight adherence to the ectoderm. These first MPs in the limb bud are the 133a MP and the retractor unguis muscle 1 (RU1) MP.

We summarize below the development of the muscles and nerves of the metathoracic limb bud from $35 \%$ to $47.5 \%$ as the context within which to describe the development of coxal muscle 133a. The details of this overall development are presented elsewhere (Ball et al., 1985; Ball and Goodman, 1985a, b). By 35\%, the segmentation of the limb bud into coxa, femur, and tibia is already evident (Fig. 3A). The N5 axonal pathway has already been pioneered by the peripheral $1 \mathrm{~B}$ and $1 \mathrm{~A}$ neurons growing toward the CNS (Bentley and Keshishian, 1982; Ho and Goodman, 1982) and the N3 pathway is being pioneered by the growth cone of the SETi motoneuron extending outward from the CNS into the limb bud. The characteristic turns in the initial N5 pathway near the $3 \mathrm{~B}$ neuron and at the $1 \mathrm{~A}$ neurons have been well described and here serve as convenient landmarks for studying the development of the 133a MP. The two 
A. $35 \%$

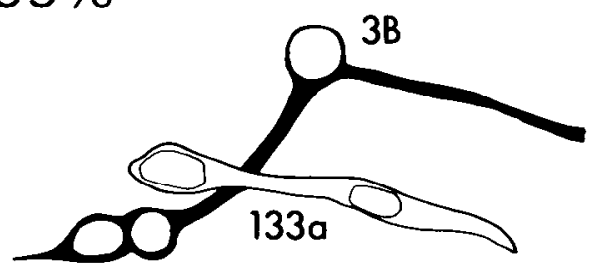

IA

B. $37.5 \%$

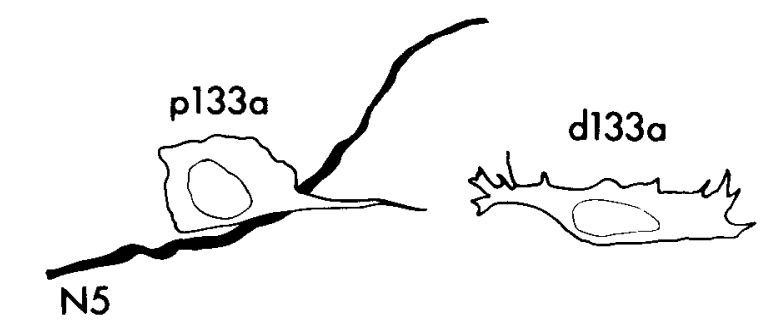

20um
D. $42.5 \%$

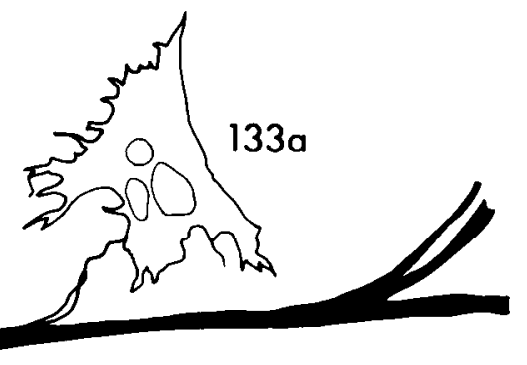

N5

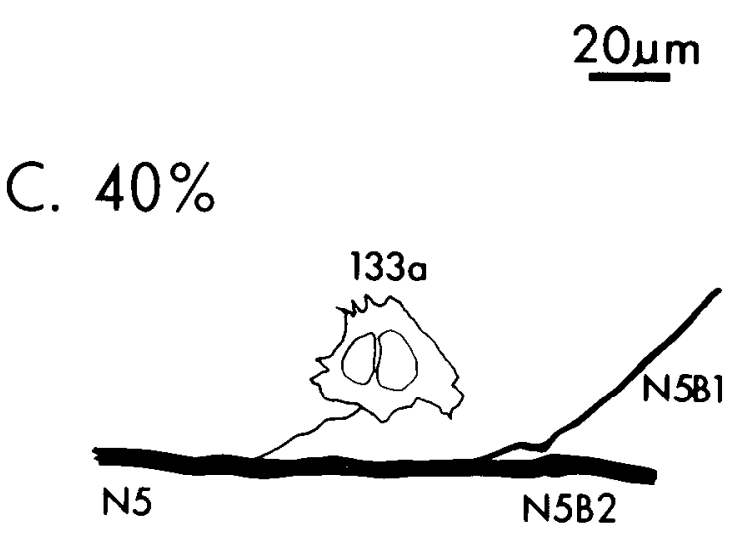

E. $45 \%$
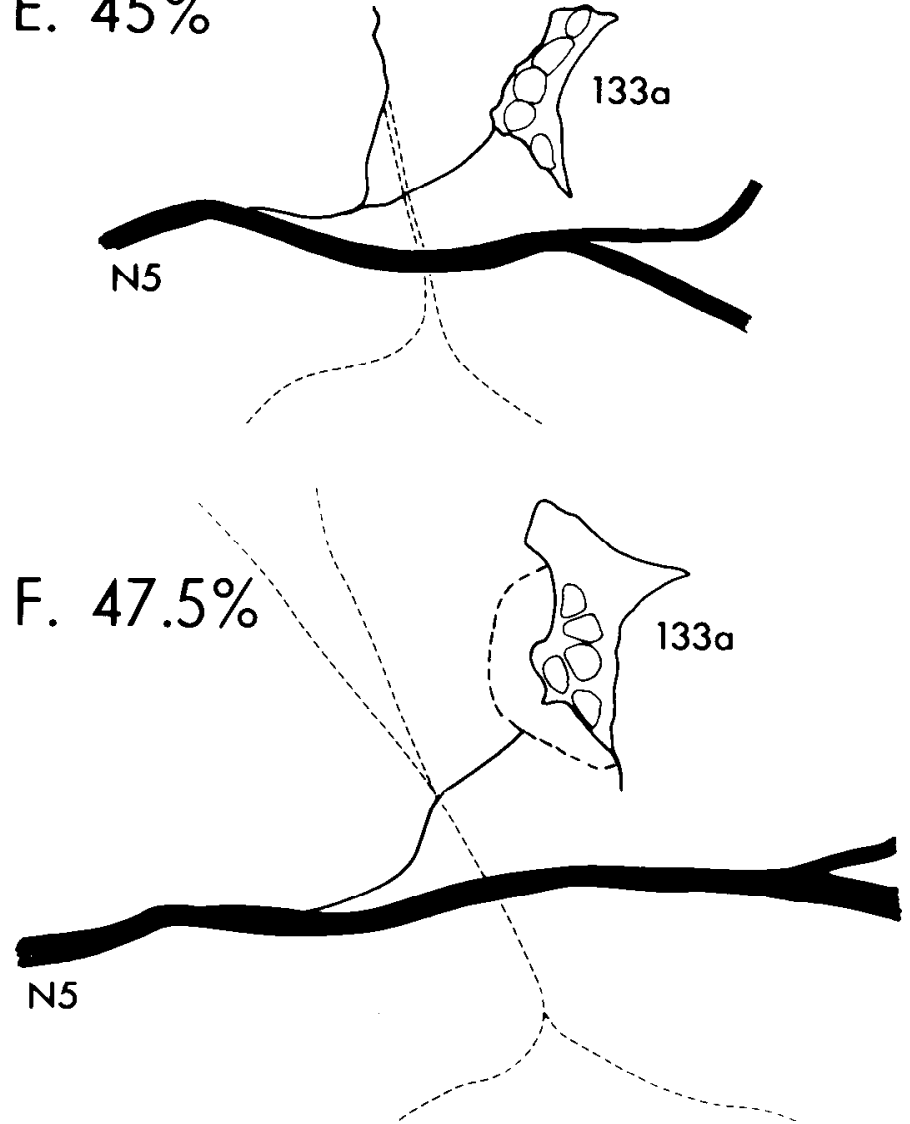

Figure 4. Development of the $133 \mathrm{a}$ MP at $2.5 \%$ intervals from $35 \%$ to $47.5 \%$ of embryonic development. All drawings are at the same scale and are

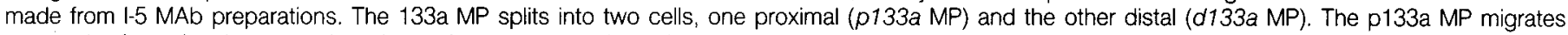

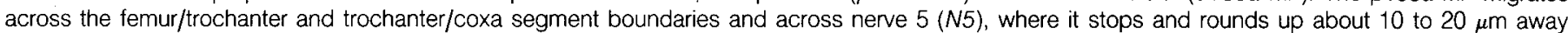

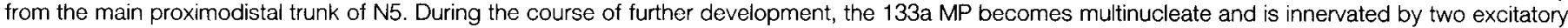
motoneurons. N5B1, N5B2, branches of nerve 5 . See the text for further details.

Figure 5. Color micrographs showing the development of the 133a neuromuscular system in the limb buds of the grasshopper embryo, as visualized with the $1-5 \mathrm{MAb}(A$ to $F)$ and with intracellular dye injections of LY followed by the anti-LY antibody and HRP immunocytochemistry $(G$ and $H)$. $A, A t 39 \%$, both meso- (upper) and metathoracic (lower) limb buds contain homologous MPs. The 133a MP in both sets of limb buds has just divided into proximal (large arrows, p133a MP) and distal (small arrows, d133a MP) MPs. Relatively few other MPs are apparent at this age. Scale bar: $100 \mu \mathrm{m}$. $B$, At $35 \%$ the $133 \mathrm{a}$ MP is in the process of dividing into proximal and distal parts. In the background are several pioneer neurons (1A and $3 B$ ) which are sending axons along a stereotyped pathway proximally toward the CNS, thus laying down the main leg nerve (N5). Scale bar: $20 \mu \mathrm{m}$. C, By $39 \%$, the 133 a MP has divided into proximal ( $p 133 a \mathrm{MP}$ ) and distal (not shown) parts. Here the first motoneuron growth cones can be seen (arrow) growing outward along N5. These initial motoneurons will innervate tibial muscles, which control the tarsus, and the flexor tibiae muscle in the femur. Scale bar: $10 \mu \mathrm{m}$. D, At $41 \%$, at this stage the p133a MP has rounded up, whereas the d133a MP has become elongated and has sent out numerous long filopodia. Some motoneuron growth cones have now left N5 (arrow) and are headed toward the tendon of the FITi MP. Scale bar: $20 \mu \mathrm{m}$. E, By 43\%, the p133a MP is triangular and contains at least two nuclei. Two motoneurons have probably already reached the MP, judging by the thickness of the nerve branch leading to it. Scale bar: $20 \mu \mathrm{m}$. $F$, The $48 \%$ stage is the latest we were able to follow the p133a MP (arrow) with the l-5 MAb. At this stage the p133a MP is on the proximal wall of the coxa. The proximal portions of the ETi and FITi MPs are shown at the right. Scale bar: $30 \mu \mathrm{m}$. G and H, These two micrographs show the same whole mount preparation at $41 \%$ of development in two different focal planes. The soma of $D_{t}$ has been penetrated with a microelectrode and $D_{t}$ and its sibling cell, to which it is dye coupled, have been filled with LY. The fixed preparation was then processed with the anti-LY antibody and HRP immunocytochemistry. The growth cone of $D_{f}$ has left N5 and is pointing at the 133a MP. The growth cone of the $D_{1}$ sibling (arrowhead) has continued extending distally toward tibial MPs. Scale bars: $10 \mu \mathrm{m}$. 


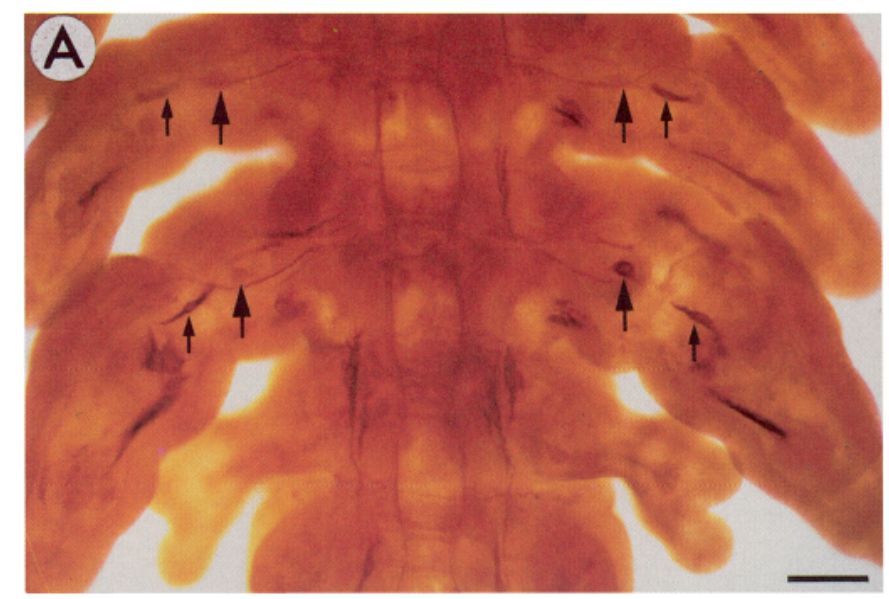

E
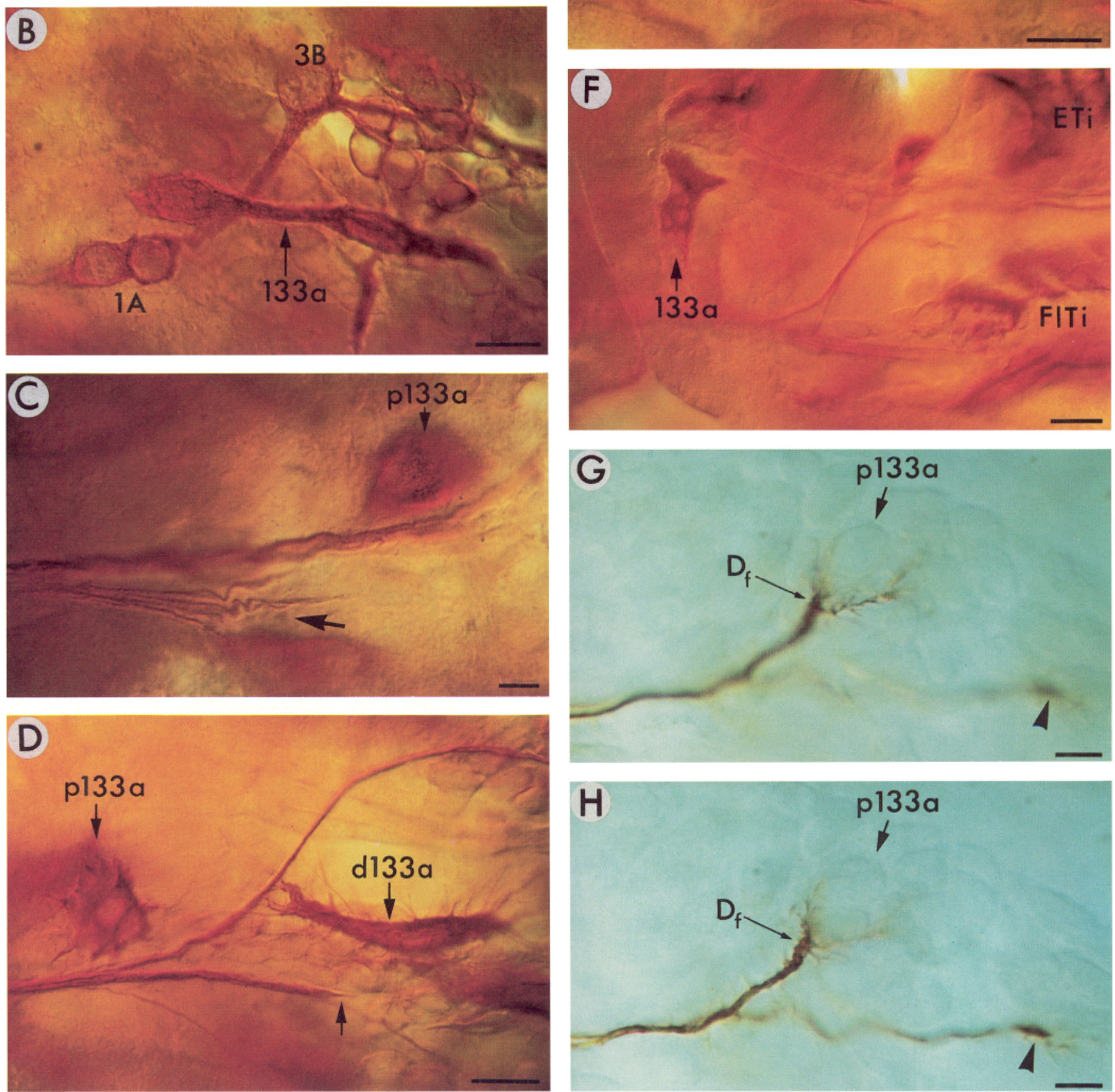

Figure 5 

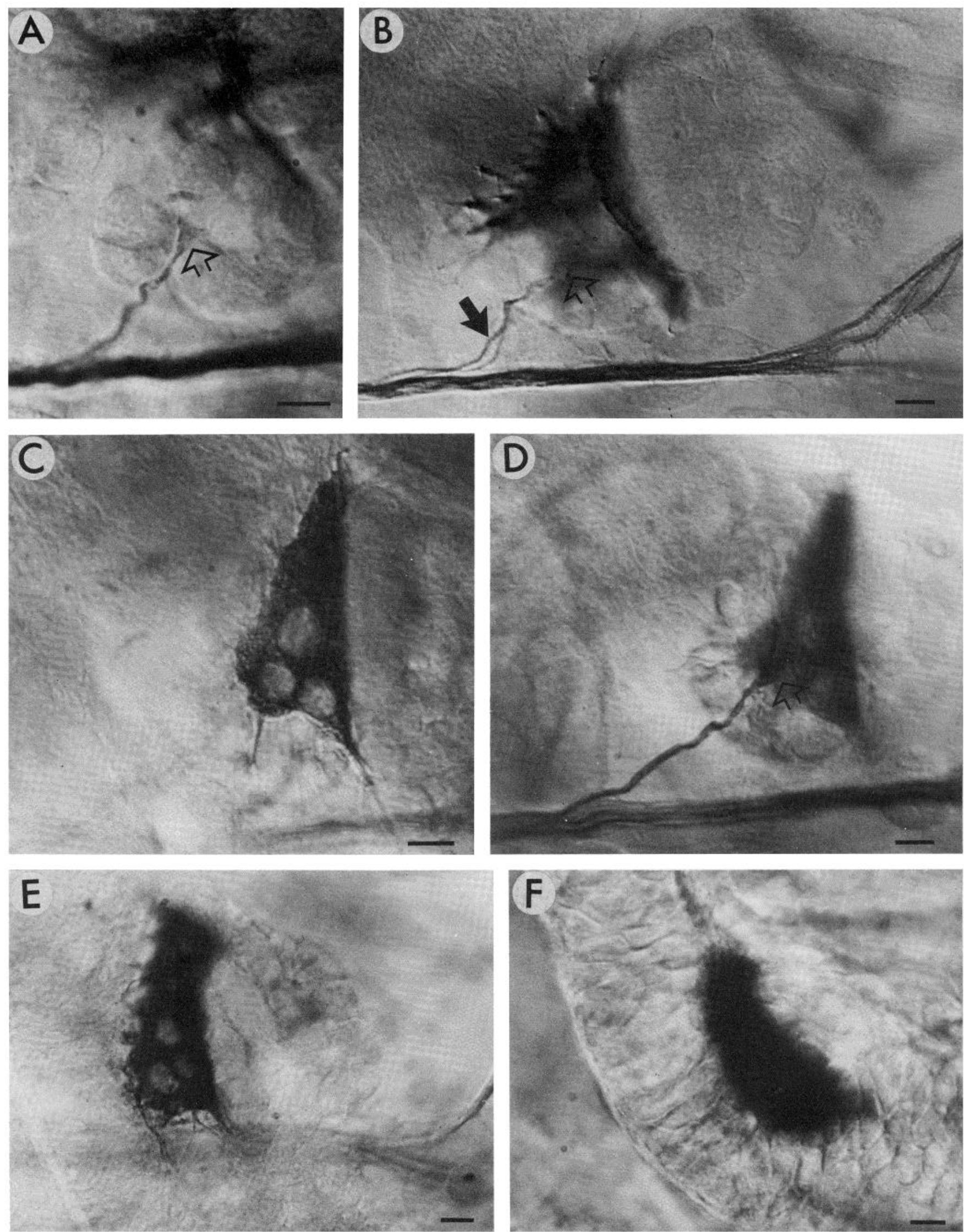

Figure 6. Embryonic development of the 133a neuromuscular system as visualized by the $1-5$ monoclonal antibody $(A$ to $E)$ and by intracellular dye injections of HRP $(F)$. Scale bars: $10 \mu \mathrm{m}$. A, At $43 \%$, the expanded growth cone (open arrow) of the first motoneuron to reach the 133a MP, the D, motoneuron, has left N5 and is here shown in contact with the mesodermal cells just under and surrounding the MP. $B$, At $43 \%$, two axons have now reached the 133a MP (solid arrow), which has extended profuse filopodia in many directions. Other methods reveal that these two growth cones are the $D_{f}$ and $\mathrm{D}_{\mathrm{s}}$ motoneurons. Note the abundant lateral filopodia extending from the axons in N5B1 and N5B2 at the right of the field. C, At 46\% the 133a MP has three nuclei and is sending out profuse filopodia in many directions. $D$, The same $133 \mathrm{aP}(46 \%)$ in a different focal plane, showing the branch from N5 innervating it. $E$, At $48 \%$ the $133 \mathrm{a} \mathrm{MP}$ is on the wall of the coxa and contains at least five nuclei. $F$, At $47 \%$, filling the $133 \mathrm{a}$ MP with HRP reveals that it is indeed a syncytium with all of the nuclei surrounded by a single membrane. 


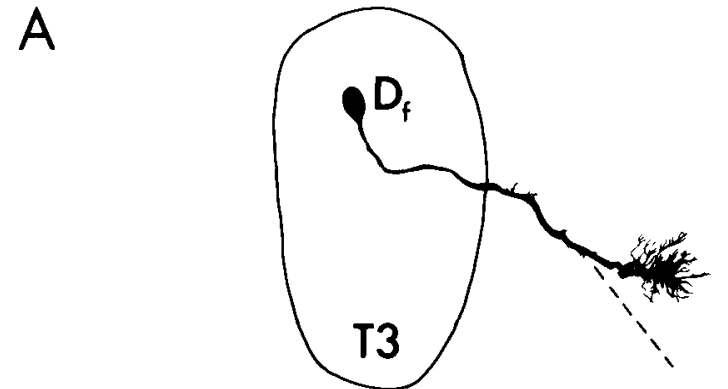

B
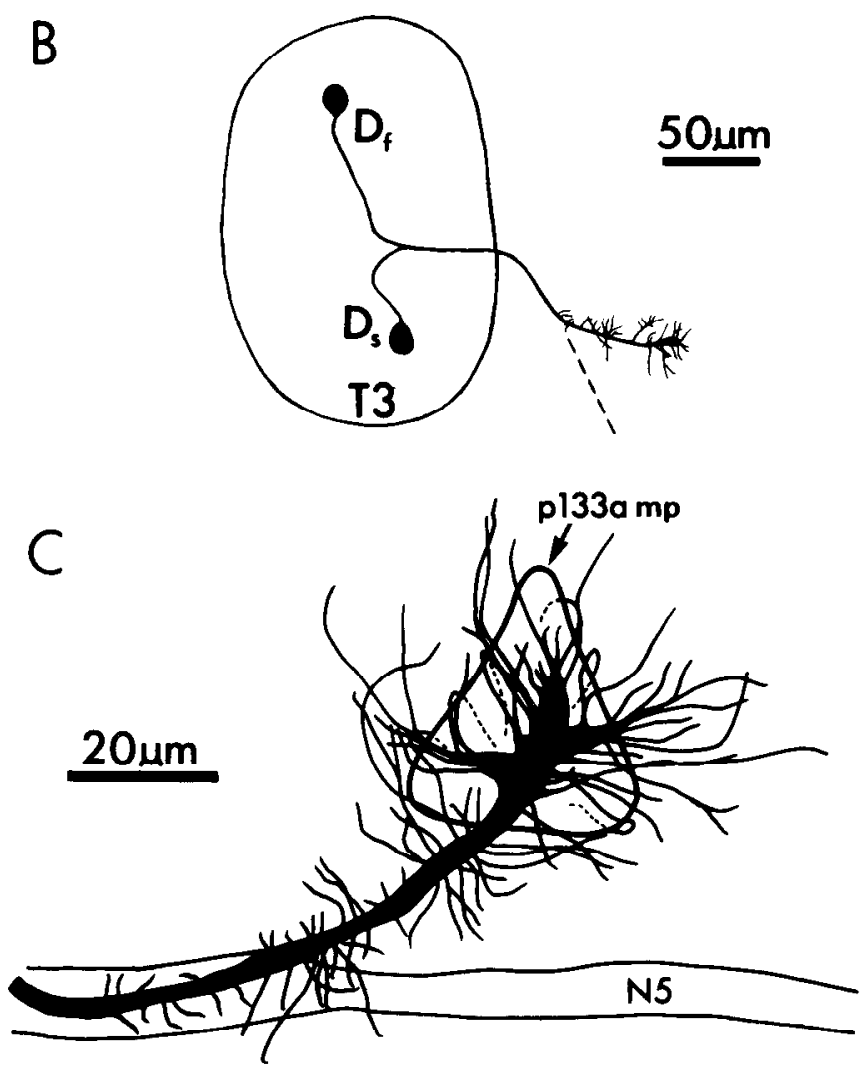

Figure 7. Innervation of the 133 a MP by two identified excitatory motoneurons during embryonic development, as visualized in preparations in which the cell bodies ( $A$ and $C$ ) or growth cones $(B)$ of the neurons have been penetrated with a microelectrode, filled with $L Y$, and processed after fixation with the anti-LY antibody and HRP immunocytochemistry. $A$ and $B$ are drawn at the same scale. $A$, At $41 \%$, the growth cone of $D_{i}$, the first cell to innervate the $133 \mathrm{a} M P$, is shown here just as it reaches the MP after leaving N5 (dashed line). Note the abundant filopodia projecting from the growth cone. $B$, At $43 \%$, a second cell, $D_{s}$, has also reached the $133 a \mathrm{MP}$. $C$, At $42 \%$, the filopodia of the $D_{f}$ growth cone surround the $133 a \mathrm{MP}$.

most prominent MPs at this stage are the binucleate 133a MP and the RU1 MP at the proximal end of the RU tendon.

By $40 \%$ of development, the muscle pioneers for the two large femoral muscles, the extensor tibiae (ETi) and flexor tibiae (FITi), and for the tibial muscies (tarsal depressor (DTa, Fig. 3) and levator tarsus (LeTa, Fig. 3)), which move the tarsus, havc appcarcd, and their associated ectodermal tendons (apodemes) have begun to invaginate (Fig. $3 B$ ). The binucleate 133a MP has split into two cells, one called the proximal (p133a) and the other the distal (d133a) 133a MP. The p133a MP has migrated proximally to its final position, and the d133a MP has begun to break up and degenerate. Other coxal muscle MPs (not shown) have appeared by this time.

Most important for this analysis, motoneuron growth cones have already extended out the N5 pathway. When the first motoneuron growth cone (which subsequently innervates a tibial muscle) reaches the $1 \mathrm{~A}$ cell bodies, it does not turn dorsally along the pathway (N5B1) toward the 3B cell but, rather, continues extending distally past the FITi MP and toward the tibial MPs (thus pioneering N5B2) (Ho and Goodman, 1982). The next motoneuron growth cones turn toward the FITi MPS along N5B3. One of the next motoneuron growth cones turns toward the 133a MP, as described below in this paper. Around $42.5 \%$, a second motoneuron growth cone turns toward the 133a MP. Between $40 \%$ and $45 \%$, the growth cone of the fast extensor tibiae motoneuron extends out from N5 and turns along N5B1 (and subsequently along N5B1D) toward the ETi MP.

The major point is that, between $37.5 \%$ and $42.5 \%$, the growth cones of many motoneurons $(>15)$ extend outward along N5 and make cell-specific choices of which way to go when they reach the region in the coxa of the 133a MP and the intersection of the three major branches of N5 (5B1, 5B2, and 5B3). Further development of these muscles and tendons takes place between $40 \%$ and $47.5 \%$ (Fig. 3C), and additional motoneuron growth cones extend out of N5.

Development of the 133a MP. The 133a MP first enlarges and begins to stain with the $1-5 \mathrm{MAb}$ around $30 \%$ of development. At this stage, the mononucleate cell is within the femur, distal to the $1 \mathrm{~A}$ pioneer neurons. By $32.5 \%$, the 133a MP has enlarged and elongated proximodistally. Furthermore, it has become binucleate. In our observations of more than 30 embryos at this stage, we have never seen the initial nucleus of the 133a MP in the process of dividing (e.g., we have never observed breakdown of the nuclear membrane or metaphase chromosomes), whereas we have seen profiles in light microscope observations that appear as if they represent a second cell with an intact nucleus fusing with the initial 133a M:P. We interpret these observations to suggest that the 133a MP becomes binucleate by cell fusion rather than by nuclear division.

The 133a MP continues to elongate proximally, with the more proximal of the two nuclei at the leading edge of this extension (Fig. $4 A$ ). The proximal extension of the 133a MP grows across the N5 pathway between the $3 \mathrm{~B}$ and $1 \mathrm{~A}$ neurons, whereas the distal portion of the 133a MP remains where it began relative to these two neurons. By $37.5 \%$, the $133 \mathrm{a} \mathrm{MP}$ is either in the process of splitting into two cells (Figs, $4 A$ and $5 B$ ) or has just completed the split (Fig. $4 B$ ), with the membrane pinching off into two cells, each of which contains one of the initial two nuclei. The two cells are referred to as the proximal (p133a) and distal (d133a) 133a MPs. We confirmed the observation that one cell split into two separate cells at this stage by intracellular injections of HRP into either the proximal edge of what appeared to be the single 133a MP (in which case both nuclei were surrounded by HRP reaction product) or the $\mathrm{p} 133 \mathrm{a}$ MP after it appeared to have migrated away from its distal portion (in which case the d133a MP was not filled).

Between $37.5 \%$ and $40 \%$, the p133a MP stops migrating and assumes its final location proximal to the turn of N5 and about 10 $\mu \mathrm{m}$ away from the main proximodistal trunk of N5 (Figs. $4 \mathrm{C}$ and 5 , $C$ and $D$ ). Thus, the p133a MP migrates across two segment boundaries in the limb bud, being born in the femur and crossing the trochanter to reach its final position in the coxa. Once it reaches this final location, the 133a MP loses its elongated shape, rounds up as a large mononucleate ceil, and extends numerous radial filopodia, some of which contact the N5 pathway only 10 to $20 \mu \mathrm{m}$ away.

Between $37.5 \%$ and $47.5 \%$, the number of nuclei in the p133a MP increases from one $(37.5 \%)$ to two $(40 \%)$ to thrce $(42.5 \%)$ to about five (45\%) to about seven ( $47.5 \%$ ) (e.g., Figs. 4 to 6$)$. We have never observed nuclear divisions within this MP, or for that matter within any of the MPs in the metathoracic limb bud, yet we often observe numerous cell divisions within the mass of smaller mesodermal cells within the same period of development. In the ETi MP, the number of nuclei increases from one to hundreds without any sign of nuclear division within the MP, although abundant divisions are apparent in the surrounding mass of mesodermal cells. 


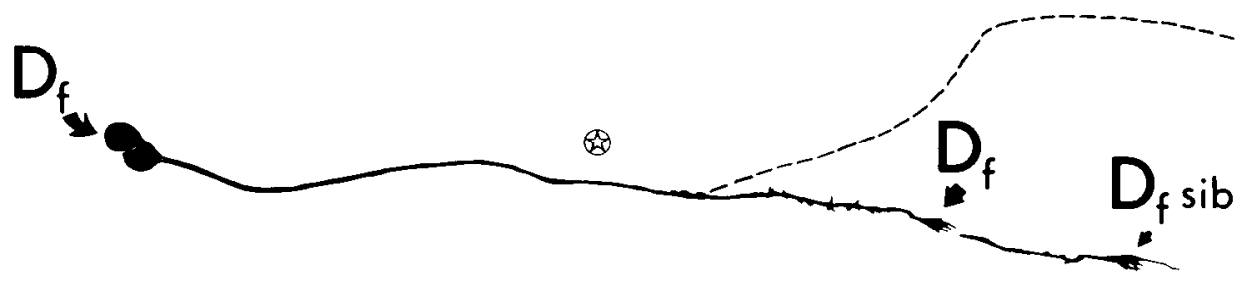

Figure 8. The ablation of the 133a MP leads to abnormal behavior of the $D_{1}$ growth cone. These drawings show the results of two experiments in which the p133a MP was ablated at around $37 \%$, the embryo was cultured for 48 hr until the growth cone of $D_{1}$ should have reached the $p 133 a M P$, and $D_{f}$ subsequently was filled with $L Y$ to reveal what its growth cone had done in this altered environment. $D_{t}$ is dye coupled to its sibling $(D, s i b)$. In both cases, the growth cone of $D_{f}$ followed that of the $D_{f}$ sibling and did not leave N5 at the normal location (star), but instead continued extending distally along N5B2 toward the tibial MPs. The dashed line shows the course of N5B1 as laid down by the early pioneer neurons.

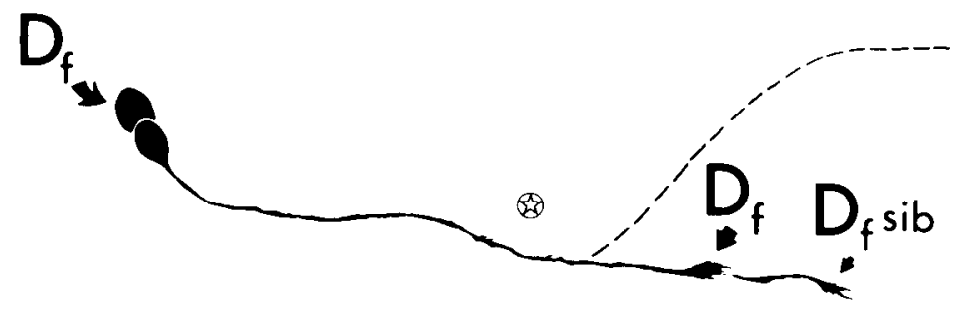

\section{$100 \mu \mathrm{m}$}

In the case of the ETi MP, extensive light and electron microscope observations, as well as colchicine and $\left[{ }^{3} \mathrm{H}\right]$ thymidine experiments, lead us to conclude that nuclear number in the MP increases by the fusion of small mesodermal cells with the MP (Ball and Goodman, 1985a). In the case of the p133a MP described here, we suggest that the same process is taking place since the nuclear number increases without evidence of nuclear division.

Around $40 \%$ of development, two important events occur in the lives of the p133a and d133a MPs. The d133a MP begins to die: its nucleus condenses and, shortly thereafter, the cell begins to break up. By $42.5 \%$ only small pieces of cellular debris are left. Before its death, the d133a MP radiated many filopodia (Fig. 5D) and (based on observations with the $1-5 \mathrm{MAb}$ ) remained uninnervated even though several motoneuron growth cones extended withiri stort filopodial grasp of its surface. About the same time as the d133a MP dies, a single growth cone leaves the N5 pathway and extends about 10 to $20 \mu \mathrm{m}$ to contact the p133a MP (Figs. $4 \mathrm{C}$ and $6 \mathrm{~A}$ ). At around $42.5 \%$ to $43 \%$ of development, a second growth cone leaves the N5 pathway and contacts the p133a MP (from here on simply called the 133a MP) (Figs. $4 D, 5 E$, and $6 B$ )

Between 35 and $55 \%$, the smaller mesodermal cells in the limb bud break up into separate masses that condense around the various MPs. By $40 \%$ of development, a mass of smaller cells has collected around the 133a MP (Fig. 6, $A$ and $B$ ); along with the 133a MP, these cells ultimately develop into the 133a muscle. We followed the Incation and further development of the 13.3a MP with the $1-5$ MAb up until about $48 \%$ of development, and with HRP injections up until about $47 \%$ of development. At $48 \%$ of development, there is still no sign at the light microscopic level of the differentiation of muscle fibers in or around the 133a MP. In the FITi and ETi MPs, which have been studied at the ultrastructural level, thick and thin filaments are first apparent at about 50\% (Ball and Goodman, 1985a, b).

Innervation of $133 a$ MP. Between $37.5 \%$ and $45 \%$ of development, I-5 MAb staining reveals two growth cones getting off the N5 pathway and extending across the $10-$ to $20-\mu \mathrm{m}$ gap to the $133 \mathrm{a}$ MP. The timing of these two events is very precise. This observation was our first indication of the specificity of motoneuron innervation early in development; we never observed additional growth cones getting off at the 133a MP and inferred from this that, during normal development, there may be no or few mistakes of innervation from the outset. As described below, the specificity of innervation at this stage by two growth cones was confirmed by intracellular dye injections which consistently revealed two and only two neurons innervating 133a.

In order to identify the two motoneurons that sequentially innervate the 133a MP, we impaled their growth cones and filled them with the fluorescent dye LY. Fortunately, at around $40 \%$ of development, when the first growth cone is spanning the 10- to 20- $\mu \mathrm{m}$ gap between N5 and the 133a MP, this growth cone can be visualized with relative ease in the living embryo using Nomarski optics and can be penetrated with a microelectrode under visual control. The $L Y$ injected inlo the growlh cone travels back to the cell body in the metathoracic ganglion. We subsequently fixed the embryo and processed it with the anti-LY antibody (Taghert et al., 1982) for better visualization using HRP immunocytochemistry.

Using this method, in more than 10 embryos we identified this first motoneuron as $D_{f}$ based on its cell body location and axon trajectory in the metathoracic ganglion; we confirmed this identification in other embryos by filling the growth cone from the cell body (Fig. 7A). The same method was used to identify the second motoneuron that innervates the $133 a \mathrm{MP}$ as $\mathrm{D}_{\mathrm{s}}$. When both motoneurons were filled with dye at around $43 \%$ of development, two cell bodies were revealed in the CNS, one of which is the $D_{f}$ motoneuron and the other the $\mathrm{D}_{\mathrm{s}}$ motoneuron (Fig. 7R). We never observed any other motoneurons innervating the 133a MP at this stage of development $(n>15)$. We do not know when $\mathrm{Cl}$ innervates 133a but infer from our intracellular dye injections that it must be after $45 \%$ of development.

Having first identified the two motoneurons that innervate the $133 \mathrm{a}$ MP between $37.5 \%$ and $45 \%$ of development, and second determined that the initial pattern of innervation was highly specific, we next wanted to examine the behavior of their growth cones and filopodia as they left N5 and extended toward the 133a MP. For example, do they appear to use some specific guidance cue for this turn, and if so, does the cue appear to be the 133a MP or, alternatively, the mass of small mesodermal cells around it? To attempt to answer this question, we penetrated the cell body of the 


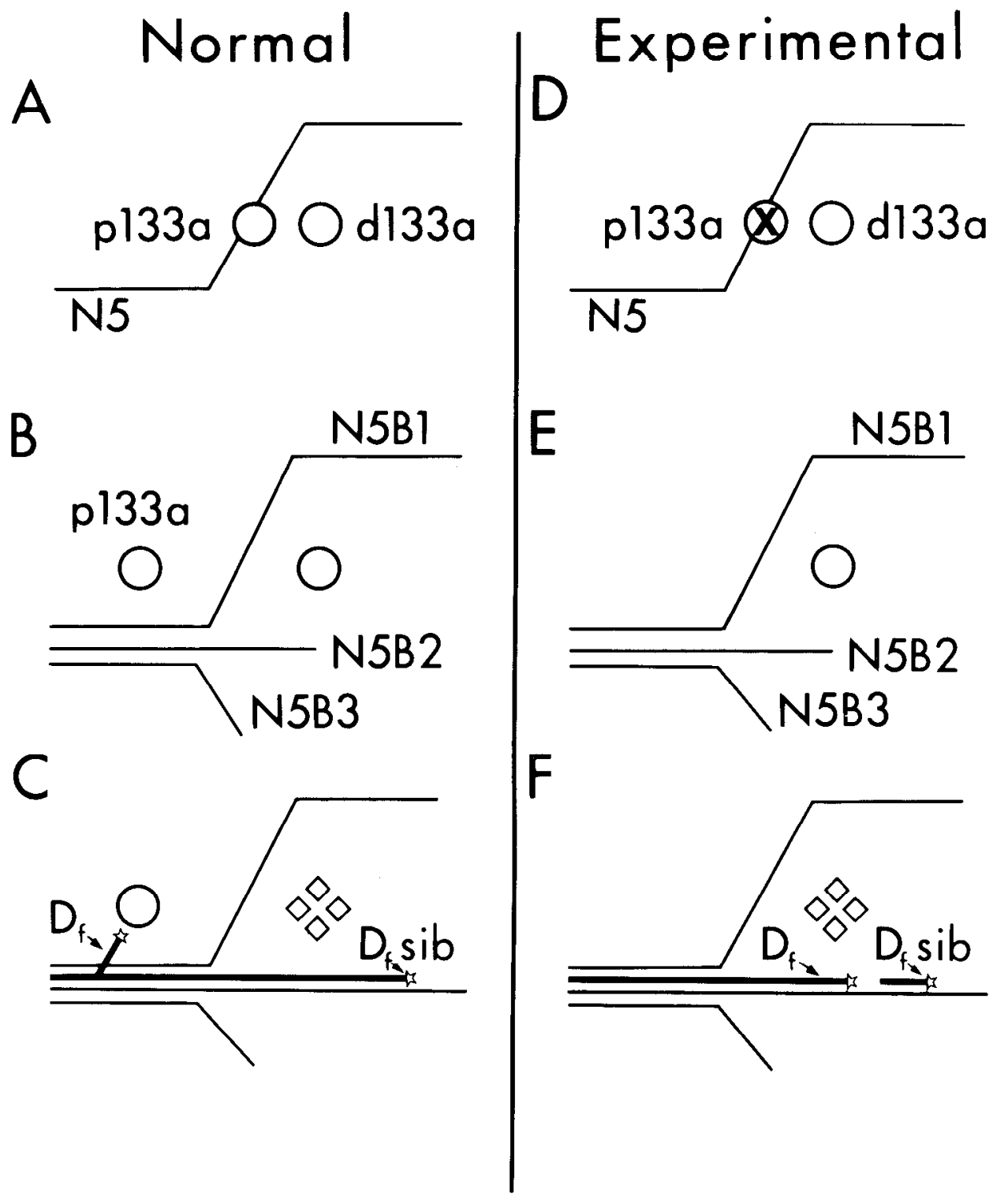

Figure 9. Summary schematic diagram showing the behavior of the $D_{f}$ growth cone in normal (left) and experimental (right) embryos. Normally, the p133a MP migrates across N5B1 and the d133a MP dies and degenerates. The p133a MP is innervated by the $D_{i}$ growth cone, whereas the $D_{1}$ sibling $\left(D_{f}\right.$ sib) continues extending distally along N5B2. When the p133a MP is ablated $(X)$, the $D_{f}$ growth cone continues extending distally, following the pathway taken by its sibling. See the text for implications.

$D_{f}$ motoneuron in the metathoracic ganglion at 41 to $42 \%$ of development with a microelectrode, iontophoretically injected $L Y$, and further processed the embryo after fixation with the anti-LY antibody and HRP immunocytochemistry (Figs. 5, $G$ and $H$, and 7 , $A$ and $C$ ). The $D_{1}$ cell body could be individually identified according to its shape and location in the ganglion.

We examined the $D_{f}$ growth cone in living preparations visualized with Nomarski optics and fixed preparations visualized with the I-5 MAb at different ages around the time when the $D_{f}$ growth cone gets off N5. From its shape and location, the $D_{\text {f }}$ growth cone appeared to be extending directly toward the 133a MP rather than toward any of the smaller mesodermal cells surrounding it. In preparations in which $D_{f}$ has been tilled with $L Y$ and processed with the anti-LY antibody, many of its filopodia appear to wrap around the 133a MP (Fig. 7C). Although some of the filopodia contact the other mesodermal cells, a disproportionate number seem to contact and wrap around the $133 \mathrm{a}$ MP, consistent with the observations of selective tilopodial aftinity displayed by other grasshopper growth cones for particular cell surfaces (e.g., Taghert et al., 1982; Bastiani and Goodman, 1984; Bastiani et al., 1984). The behavior of the $D_{f}$ filopodia is currently being examined at the ultrastructural level ( $E$. E. Ball and C. S. Goodman, manuscript in preparation). From light microscopic studies using the anti-LY antibody, we infer that the $D_{f}$ growth cone specifically cues on the 133a MP, most likely by the selective affinity of its filopodia for the surface of the 133a MP. We tested this hypothesis as described in the next section.

In the process of dye injecting $D_{f}$ in order to examine the behavior of its growth cone and filopodia, we were also able to observe the behavior of the growth cone of its sibling, as described below. At this stage of development, the $D_{t}$ motoneuron is dye coupled to a single neighboring cell body (located lateral and posterior to $D_{f}$ ) with a very similar axonal morphology. By following these two neurons back in development in sequentially younger embryos, we were able to determine that they are siblings that arise from the division of one of the first ganglion mother cells from neuroblast 2-2. The growth cones of the two sibling motoneurons initially follow the same pathway, extending posteriorly and then laterally within the segmental ganglion to exit N5. The growth cone of the $D_{1}$ sibling appears often to be slightly leading (i.e., distal to) the $D_{f}$ growth cone; the two cells are individually identified by their relative cell body positions. Although the two sibling growth cones initially behave similarly, when they extend across the coxa of the limb bud, they behave quite differently. The $D_{1}$ sibling growth cone extends past the $133 a$ MP (which is already in its final location and extending profuse filopodia) and continues to grow distally toward the tibia to innervate one of the tibial muscles. The $D_{f}$ growth cone, in contrast, gets off the N5 
pathway to innervate the 133a MP (Figs. 5, $G$ and $H$, and $7 C$ ). These two growth concs make their coll specific choices in the coxa while still dye coupled to one another.

Not only does the $\mathrm{D}_{\mathrm{f}}$ sibling growth cone appear to contact the filopodia of the 133a MP and yet not get off N5 to innervate it, but during this same period of development many other motoneuron growth cones $(>15)$ extend out along the N5 pathway and do not innervate the 133a MP. Because (i) the 133a MP is about 10 to 20 $\mu \mathrm{m}$ from N5 and some of its profuse filopodia extend toward and appear to contact the N5 axon bundle, and (ii) all of the growth cones extending out N5 themselves appear to extend profuse filopodia, we infer that these other growth cones make filopodial contact with the 133a MP or its filopodia and yet do not get off N5 to innervate it. These putative cellular contacts, inferred from observations at the light level, are presently being investigated at the ultrastructural level (E. E. Ball and C. S. Goodman, studies in progress).

Ablation of the 133a MP. We ablated the p133a MP at around $37 \%$ of development (Fig. 4, $A$ and $B$ ), just as the p133a MP was extending proximally across the N5 pathway. Ablating the p133a MP at this early stage has two advantages. First, it allows time for the cellular debris to be cleared away by other embryonic cells. Second, and most important, it eliminates complications in interpretation by removing the MP at a distance some $50 \mu \mathrm{m}$ distal to where it normally becomes innervated. The ablations were performed using a microelectrode, and embryos were cultured for about $48 \mathrm{hr}$. During this period, the embryos developed about $5 \%$ to a stage equivalent to $42 \%$ of normal development. After culturing, the $D_{f}$ neuron (and its sibling by dye coupling) were filled with $L Y$ and, after fixation, were processed with the anti-LY antibody and HRP immunocytochemistry.

When the p133a MP was ablated at $37 \%$ of development, it was not replaced (as indicated by both Nomarski optics observations and I-5 MAb preparations). The smaller mesodermal cells in the area did not surround dil MP as they normally do and did not condense into a tight mass. The growth cone of the $D_{f}$ sibling extended as normal out along N5 and toward the tibia along N5B2 (Fig. 8). The growth cone of $D_{f}$, however, behaved abnormally, extending past the point in the coxa where it normally gets off to innervate the $133 \mathrm{a}$ MP and, instead, continuing to extend distally along N5. In fact, in the 11 embryos examined, it always followed the route taken by its sibling (N5B2) and extended distally toward the tibia (Fig. 8). Because of the limits of the embryo culture system, we were unable to determine the eventual fate (survival versus death, and innervation if it survives) of the $D_{f}$ motoneuron.

In each experimental embryo, the contralateral metathoracic leg served as an internal control for normal development. Moreover, in those embryos in which we attempted but failed to ablate the p133a MP, all subsequent events occurred normally, including the proximal migration of the p133a MP and its innervation by the $D_{f}$ growth cone.

The results, which are summarized in Figure 9, clearly indicate that the 133a MP is necessary for the specific guidance of the $D_{1}$ growth cone off $\mathrm{N} 5$ and into the mesoderm at that location.

\section{Discussion}

Two conclusions about the mechanisms generating neuromuscular specificity in the grasshopper embryo arise from the results presented in this paper. The first concerns the specificity of the normal pattern of innervation, and the second concerns the specific role played by the MPs in generating that pattern.

During normal development, motoneuron growth cones innervate the appropriate muscle with a high degree of specificity. We have never observed mistakes in the pattern of initial innervation of the 133a MP, and we infer from this that individual motoneuron growth cones are highly specified to follow a series of guidance cues and innervate the appropriate muscle. These guidance cues appear to include a series of selective fasciculation choices both within the CNS and in the periphery, and perhaps other cues in the periphery as well. Ultimately, each motoneuron growth cone makes a decision to get off an axon bundlc and extcnd into the appropriate region of mesoderm before the muscle has differentiated. More than 15 other motoneurons have their axons in N5 and innervate muscles distal to the 133a MP (e.g., Burrows, 1975). Moreover, their growth cones, including that of the $D_{f}$ sibling, extend out along N5 within about 10 $\mu \mathrm{m}$ of the 133a MP (and within grasp of both the motoneuron's and MP's filopodia) without getting off. However, the $D_{f}$ and, later, the $D_{s}$ growith cones do get off, indicating a high degree of specificity in the selective affinities of their growth cones for particular regions of mesoderm.

The $D_{1}$ growth cone appears to be specifically guided by the $133 \mathrm{a}$ MP rather than by the mass of smaller mesodermal cells around it. Moreover, when the 133a MP is ablated, the $D_{f}$ growth cone does not show a high affinity for the remaining mesodermal cells but, rather, extends past them and continues to grow distally (Fig. 9). These results support the hypothesis that the 133a MP rather than the other mesodermal cells provides the specific guidance cue for the $D_{f}$ growth cone. The high affinity shown by the filopodia of the $D_{f}$ growth cone for the surface of the 133a MP suggests that the 133a MP is specifically labeled on its surface. Alternatively, the smaller mesodermal cells may also be involved in the specific guidance of the $D_{f}$ growth cone, in which case they must be induced to express the appropriate cues by the presence of the 133a MP, since in its absence, the $D_{f}$ growth cone extends past them. We favor the first alternative because, during normal development, the $D_{f}$ growth cone extends toward and selectively contacts the $133 \mathrm{a}$ MP in preference to the surrounding mesoderm cells. Therefore, we conclude that the 133a MP is the guidance cue for the $D_{f}$ growth cone; we cannot, however, definitively draw the same conclusion for the $D_{\mathrm{s}}$ growth cone because it may be cuing either on the $133 \mathrm{a}$ MP or, alternatively, on the axon of $D_{f}$ which has preceded it. Further experiments are necessary to distinguish between these two alternatives.

Thus, it appears that MPs are differently labeled from other myoblasts, and that different MPs themselves may be differentially labeled, most likely by surface molecules. Interestingly, three monoclonal antibodies (the Mes-2, Mes-3, and Mes-4 MAbs), which recognize surface antigens on subsets of embryonic neurons in the grasshopper CNS (Kotrla and Goodman, 1984), also recognize a surface antigen on all of the muscle pioneers. Although these antibodies do not seem to distinguish between different MPs, they do distinguish between the MPs and the mass of smaller myoblasts which do not express any of the three surface antigens. Whether additional surface labels exist which distinguish among different MPs remains to be determined.

\section{References}

Anderson, D. T. (1972) The development of hemimetabolous insects. In Developmental Systems: Insects, S. J. Counce and C. H. Waddington, eds., Vol. 1, pp. 95-163, Academic Press, Inc., New York.

Bacon, J. P., and J. S. Altman (1977) A silver intensification method for cobalt-filled neurons in whole mount preparations. Brain Res. 138: 359363.

Ball, E. E., and C. S. Goodman (1985a) Muscle development in the grasshopper embryo. II. Syncytial origin of the extensor tibiae muscie pioneers. Dev. Biol., in press.

Ball, E. E., and C. S. Goodman (1985b) Muscle development in the grasshopper embryo. III. Sequential origin of the flexor tibiae muscle pioneers. Dev. Biol., in press.

Ball, E. E., R. K. Ho, and C. S. Goodman (1985) Muscle development in the grasshopper embryo. i. Muscles, nerves, and apodemes in the metathoracic leg. Dev. Biol., in press

Bastiani, M. J., and C. S. Goodman (1984) Neuronal growth cones: Specific interactions mediated by filopodial insertion and induction of coated vesicles. Proc. Natl. Acad. Sci. U. S. A. 81: 1849-1853.

Bastiani, M. J., J. A. Raper, and C. S. Goodman (1984) Pathfinding by neuronal growth cones in grasshopper embryos. III. Selective affinity of the $G$ growth cone for the $P$ cells within the A/P fascicle. J. Neurosci. 4: 2311-2328. 
Bastiani, M. J., S. DuLac, and C. S. Goodman (1985) The first growth cones in insect embryos: Model system for studying the development of neuronal specificity. In Model Neural Networks and Behavior, A. Selverston, ed., Plenum Press, New York, in press.

Bate, C. M. (1976) Embryogencsis of an insect norvous system. I. ^ map of the thoracic and abdominal neuroblasts in Locusta migratoria. J. Embryol. Exp. Morphol. 35: 107-123.

Bentley, D., and $\mathrm{H}$. Keshishian (1982) Pathfindirly by periphteral pioneer neurons in grasshoppers. Science 218: 1081-1088.

Bentley, D., H. Keshishian, M. Shankland, and A. Toroian-Raymond (1979) Quantitative staging of embryonic development of the grasshopper, Schistocerca nitens. J. Embryol. Exp. Morphol. 54: 47-74.

Bräunig, P. (1982) The peripheral and central nervous organization of the locust coxa-trochanteral joint. J. Neurobiol. 13: 413-433.

Bräunig, P., R. Hustert, and H. J. Pflüger (1981) Distribution and specific central projections of mechanoreceptors in the thorax and proximal leg joints of locusts. I. Morphology, location and innervation of internal proprioceptors of pro- and metathorax and their central projections. Cell Tissue Rcs. 216: 5777.

Burrows, M. (1973) Physiological and morphological properties of the metathoracic common inhibitory neuron of the locust. J. Comp. Physiol. 82: $59-78$.

Burrows, M. (1975) Integration by motoneurons in the central nervous system of insects. In Simple Nervous Systems, P. N. R. Usherwood and D. R. Newth, eds., pp. 345-379, Arnold, London.

Campbell, J. I. (1961) The anatomy of the nervous system of the mesothorax of Locusta migratoria migratorioides R. and F. Proc. R. Zool. Soc. Lond. 137: $403-432$

Chang, S., R. Ho, and C. S. Goodman (1983) Selective groups of neuronal and mesodermal cells recognized early in grasshopper embryogenesis by a monoclonal antibody. Dev. Brain Res. 9: 297-304.

Ferguson, B. A. (1983) Development of motor innervation of the chick following dorsal ventral limb bud rotations. J. Neurosci. 3: 1760-1772.

Goodman, C. S., M. J. Bastiani, C. Q. Doe, S. du Lac, S. L. Helfand, J. Y. Kuwada, and J. B. Thomas (1984) Cell recognition during neuronal developmenl. Science 225: 1271-1279.

Ho, R. K., and C. S. Goodman (1982) Peripheral pathways are pioneered by an array of central and peripheral neurones in grasshopper embryos. Nature 297: 404-406.

Ho, R. K., E. E. Ball, and C. S. Goodman (1983) Muscle pioneers: Large mesodermal cells that erect a scaffold for developing muscles and motoneurones in grasshopper embryos. Nature 301: 66-69.

lles, J. F. (1972) Structure and synaptic activation of the fast coxal depressor motoneurone of the cockroach, Periplaneta americana. J. Fxp. Biol. 56: 647-656.

Kotrla, K. J., and C. S. Goodman (1984) Transient expression of a surface antigen on a small subset of neurons during embryonic development. Nature 311: 151-153.

Lance-Jones, C., and L. Landmesser (1980a) Motoneurone projection pat terris in ernbryonic chick lirntus folluwirig partial deletions of the spinal cord J. Physiol. (Lond.) 302: 559-580

Lance-Jones, C., and L. Landmesser (1980b) Motoneurone projection pat- terns in the chick hind limb following early partial reversals of the spinal cord. J. Physiol. (1.ond.) 302: 581-602.

Lance-Jones, C., and L. Landmesser (1981a) Pathway selection by chick lumbosacral motoneurons during normal development. Proc. R. Soc. Lond. (Biol.) 214: 1-18

Lance-Jones, C., and L. Landmesser (1981b) Pathway selection by embryonic chick motoneurons in an experimentally altered environment. Proc. R. Soc. Lond. (Biol.) 214: 19-52.

Pearson, K. G., and C. R. Fourtner (1973) Identification of the somata of common inhibitory motoneurons in the metathoracic ganglion of the cockroach. Can. J. Zool. 51: 859-866.

Pearson, K. G., and J. F. lles (1971) Innervation patterns of the coxal depressor muscles of the cockroach, Periplaneta americana. J. Exp. Biol. 54: $215-232$

Pitman, R. M., C. D. Tweedle, and M. J. Cohen (1972) Branching of central neurons: Intracellular cobalt injection for light and electron microscopy. Science 176: 412-414.

Pitman, R. M., C. D. Tweedle, and M. J. Cohen (1973) The dendritic geometry of an insect common inhibitory neuron. Brain Res. 60: 465-470.

Raper, J. A., M. J. Bastiani, and C. S. Goodman (1983a) Pathfinding by neuronal growth cones in grasshopper embryos. I. Divergent choices made by the growlh cones of sibling neurons. J. Neurusci. 3: 20-30.

Raper, J. A., M. J. Bastiani, and C. S. Goodman (1983b) Pathfinding by neuronal growth cones in grasshopper embryos. II. Selective fasciculation onto specitic axonal pathways. J. Neurosci. 3: 31-41.

Raper, J. A., M. J. Bastiani, and C. S. Goodman (1983c) Guidance of neuronal growth cones: Selective fasciculation in the grasshopper embryo. Cold Spring Harbor Symp. Quant. Biol. 48: 587-598.

Raper, J. A., M. J. Bastiani, and C. S. Goodman (1984) Pathfinding by neuronal growth cones in grasshopper embryos. IV. The effects of ablating the $A$ and $P$ axons upon the behavior of the $G$ growth cone. J. Neurosci. 4: $2329-2345$.

Snodgrass, R. C. (1929) The thoracic mechanism of a grasshopper and its antecedents. Smithsonian Misc. Collect. 82: 1-111.

Taghert, P. H., M. J. Bastiani, R. K. Ho, and C. S. Goodman (1982) Guidance of pioneer growth cones: Filopodial contacts and coupling revealed with an antibody to Lucifer Yellow. Dev. Biol. 94: 391-399.

Taghert, P. H., C. Q. Doe, and C. S. Goodman (1984) Cell determination and regulation during development of neuroblasts and neurones in grasshopper embryo. Nature 307: 163-164.

Whitelaw, V., and M. Hollyday (1983a) Thigh and calf discrimination in the motor innervation of the chick hindlimb following deletions of limb segments. J. Neurosci. 3: 1199-1215.

Whitelaw, V., and M. Hollyday (1983b) Position-dependent motor innervation of the chick hindlimb following serial and parallel duplications of limb segments. J. Neurosci. 3: 1216-1225.

Whitelaw, V., and M. Hollyday (1983c) Neural pathway constraints in the motor innervation of the chick hindlimb following dorsoventral rotations of distal limb segments. J. Neurosci. 3: 1226-1233.

Whitington, $P$. M. and E. Seifert (1981) Identified neurons in an insect embryo: The pattern of neurons innervating the metathoracic leg of the locust. J. Comp. Neurol. 200: 203-212. 